\title{
How Will Copper Contamination Constrain Future Global Steel Recycling?
}

\author{
Katrin E. Daehn, André Cabrera Serrenho, and Julian M. Allwood*(0) \\ Department of Engineering, University of Cambridge, Cambridge CB2 1PZ, United Kingdom \\ Supporting Information
}

ABSTRACT: Copper in steel causes metallurgical problems, but is pervasive in end-of-life scrap and cannot currently be removed commercially once in the melt. Contamination can be managed to an extent by globally trading scrap for use in tolerant applications and dilution with primary iron sources. However, the viability of long-term strategies can only be evaluated with a complete characterization of copper in the global steel system and this is presented in this paper. The copper concentration of flows along the 2008 steel supply chain is estimated from a survey of literature data and compared with estimates of the maximum concentration that can be tolerated in steel products. Estimates of final steel demand and scrap supply by sector are taken from a global stocksaturation model to determine when the amount of copper in the steel cycle will exceed that which can be tolerated. Best estimates

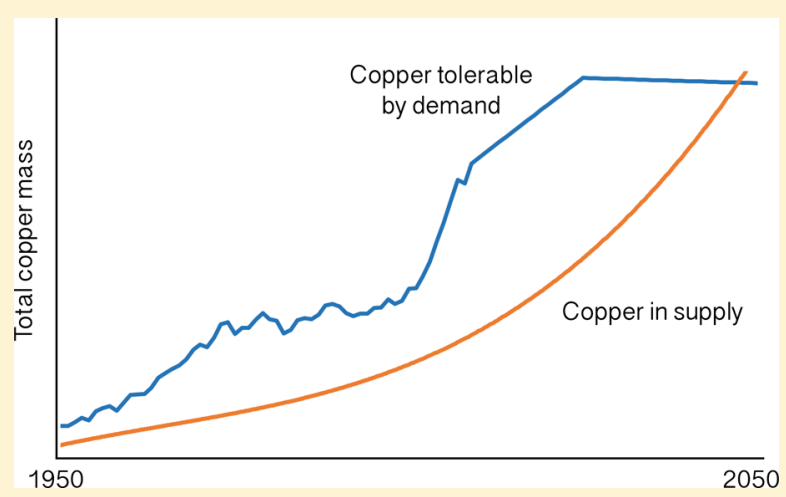
show that quantities of copper arising from conventional scrap preparation can be managed in the global steel system until 2050 assuming perfectly coordinated trade and extensive dilution, but this strategy will become increasingly impractical. Technical and policy interventions along the supply chain are presented to close product loops before this global constraint.

\section{INTRODUCTION}

Steel is the world's most recycled material, with end-of-life recovery rate estimates as high as $90 \% .^{1}$ Making steel from scrap in an Electric Arc Furnace (EAF) leads to around onethird the greenhouse gas emissions associated with steelmaking from ore. ${ }^{2}$ As steel production accounts for approximately $25 \%$ of industrial emissions, ${ }^{3}$ further reliance on recycling to supply demanded products is key to climate change mitigation. ${ }^{4}$

Oda et al. ${ }^{5}$ show that steel recycling has historically been constrained by the availability of scrap. Using a dynamic stock model, Pauliuk et al. ${ }^{6}$ find that by 2050 the global supply of end-of-life scrap will triple from current volumes. From this expanding volume of scrap, Allwood ${ }^{7}$ argues that all projected future growth in demand for steel could be met by recycling, but it is unknown whether the secondary route can supply the demanded quality requirements.

End-of-life steel scrap is often contaminated with other metals. If these cannot be extracted from the EAF melt, then they are known as "tramp elements." Nakajima et al. ${ }^{8}$ identify the key tramp elements in steel recycling by thermodynamic analysis, of which copper and tin are most important. Concentrations of copper over 0.1 wt \% cause hot shortness, a phenomenon leading to surface cracking in hot rolling and forming. Tin exacerbates hot shortness, even at concentrations as low as 0.04 wt \%. Rod et al. ${ }^{9}$ review the mechanism of hot shortness, which is now well understood.

Copper is pervasive in end-of-life scrap, originating mostly from copper wires and motors in automobiles, appliances, and machinery that attach to steel during shredding. ${ }^{10}$ Tin contamination originates from packaging tinplate, which makes up a much smaller $(<1 \%)$ portion of the scrap stream, ${ }^{11}$ and can be isolated and treated more readily prior to melting. The focus of this paper is therefore on copper, as it is currently the main barrier to producing high quality steel from recycled scrap.

Björkman et al. ${ }^{12}$ state in their overview of steel recycling that dilution with virgin iron, or less contaminated scrap sources, is the only commercially practiced solution for reducing the concentration of tramp elements in the steel melt. Hand-picking of copper from the waste stream is often practiced; however, contaminated scrap often goes to more forgiving applications. Reinforcing bar has a nominal tolerance of 0.4 wt \% copper, while flat products requiring excellent formability and surface properties have the most stringent limits (less than $0.06 \mathrm{wt} \%$ copper for drawing steels), ${ }^{13}$ so end-of-life scrap is generally not a significant supply source for these products. ${ }^{14}$ Nakamura et al. ${ }^{15}$ use input-output analysis to show most end-of-life scrap flows to use in construction and minimally to transportation, industrial equipment and goods sectors.

Received: February 23, 2017

Revised: April 21, 2017

Accepted: April 26, 2017

Published: April 26, 2017 
Copper therefore limits the applicability of recycled steel. In a model tracing multiregional steel flows to 2100 , Pauliuk et al. ${ }^{16}$ reveal significant losses can occur from trade patterns, recovery, and remelting, but did not explicitly track tramp elements. Country-level analyses in Japan ${ }^{17,18}$ have found that the severity of the copper contamination problem will increase over time. Pauliuk et al. ${ }^{19}$ investigated the feasibility of a circular steel economy in China to 2100 and found quality constraints were likely to occur once demand for construction steel plateaus and the scrap supply increases, such that old scrap would need to be used for transportation equipment and appliances after 2030. Similar trends were discussed by Matsubae et al. ${ }^{20}$ in Japan. However, trends characterized by these studies are dependent on the boundary conditions set. The authors of the circularity study in China noted that excess scrap could be exported to regions with per capita stocks at preindustrial levels such as India, and were unsure of the extent to which this could delay or eliminate impending quality constraints. Igarashi et al. ${ }^{21}$ modeled Japanese steel scrap export scenarios and found that export choices determine whether there is an increasing or decreasing trend in copper concentration. A 1997 study by Noro et al. ${ }^{17}$ predicted that 155-300 Mt of scrap would be unusable due to copper concentration by 2015, but piling scrap within country borders will not take place so long as there is use for it elsewhere. Indeed, while previous studies advised that the copper contamination problem will worsen, Björkman et al. ${ }^{12}$ report that the average copper content in secondary steel has actually decreased. Increases in global primary production in the last 20 years have abated the problem so far and in an overview of the steel scrap market, Söderholm et al. ${ }^{22}$ claim that to date international trade has ensured that scrap flows to appropriate uses. While considering global vehicle recycling, Gesing ${ }^{46}$ recommends the unrestricted flow of scrap metal between markets and geographical locations for a sustainable metal system. However, in contrast to the regional studies mentioned above, this effect of international trade can only be projected into the future by a model of global scope. Only one such global analysis has been identified. Ekvall et al. ${ }^{23}$ use a hypothetical scenario in which scrap supply and steel demand were equal. The goal of the study was to demonstrate the viability of applying pinch analysis to global material flows, and the authors cautioned that the study should not be interpreted as a realistic characterization of copper in the steel system.

The primary aim of this paper is therefore to characterize copper in the global steel system presently, and provide a basis for understanding how contamination arising from current scrap preparation practice and accumulation will constrain future steel recycling. For how long can dilution, scrap mixing, and international trade be used to manage copper, considering the tolerance of demanded products? A secondary aim is to ask the same question for the much more demanding application of automobiles. What would be required to allow a closed-loop or "circular economy" approach to car production, with new car bodies made from steel recycled from old cars? Nakamura et al. $^{24}$ used a dynamic material flow analysis to show that only 7$8 \%$ of recovered car steel is recycled back into the automotive sector. Could this figure be increased significantly in future?

\section{METHODOLOGY}

A complete literature review and cataloguing of the scope, methodology and findings of previous relevant studies can be found in the Supporting Information (SI). A mapping of steel flows in the whole system from raw materials to products with estimated compositions does not exist, but is needed to characterize copper's presence in the global steel system. Section 2.1 describes how the copper concentrations of flows in the 2008 steel supply chain were estimated. The copper tolerances of end-use products were estimated, which establishes the quality requirements of the four end-use sectors: transportation, industrial equipment, construction, and metal goods. This characterization is coupled with results from a stock-driven model predicting the quantities of available steel scrap and demand by the four end-use sectors, as described in Section 2.2, to estimate when copper tolerances will be exceeded and understand the product categories end-of-life scrap must be used for in the future. This analysis establishes the extent that dilution and globally distributing scrap sources to tolerant applications can manage copper. However, open product loops must also be considered as a constraint caused by contamination. Section 2.3 examines the potential for a closedloop in automobile steel, one of the most demanding and important steel applications. Overall, this is the first analysis to begin from a physical model of the steel supply chain and apply stock-based projections to understand copper contamination in steel recycling. Further details of the methods and data used are given in the SI.

2.1. End-of-Life Scrap and Copper in the Present Global Steel System. Cullen et al.'s ${ }^{11} 2008$ Sankey diagram, constructed using Material Flow Analysis (MFA) to visualize tabulated information from a range of sources in a map ${ }^{25}$ of the global steel supply chain, is used as a framework on which to develop an analysis of copper concentration data and show how primary and secondary (EAF) steel may distribute to final products. The process of compiling and reconciling available data to inform the picture is presented in Section S2.1 of the SI file, and summarized here. It was assumed that all end-of-life scrap was charged to the EAF (consistent with Nakamura et al. ${ }^{15}$ ), with only forming and fabrication scrap charged to the oxygen blown converter. Only Hatayama et al. ${ }^{26}$ and Pauliuk et al. ${ }^{6}$ provide estimates on the breakdown of end-of-life scrap by type at a global scale. Pauliuk et al.'s ${ }^{6}$ estimates by four end-uses (transport, industrial equipment, construction and goods) are used, and the copper concentration of end-of-life scrap is estimated through this categorization. An estimate for the average copper concentration of primary and EAF steel streams at a global scale is made from summing these scrap categories. Cast iron and cast steel are treated separately, as copper does not have the same metallurgical effects on these products. Cullen et al.'s ${ }^{11}$ estimates on the quantities of primary and EAF steel cast into each shape are kept, with the addition of one flow of $8 \mathrm{Mt}$ of EAF steel to slab casting to account for EAF thinslab casting in the U.S. ${ }^{27}$ The flow of primary and EAF steel from casting to final products cannot be determined from the available literature, so it is estimated on a pro-rota basis. The drawn difference in casting capability can be confirmed by work from worldsteel, ${ }^{47}$ which uses plant data to conclude that globally most BOF's produce flat products, and most EAF's produce long products. There are yield losses at each process along the supply chain, as estimated by Cullen et al., ${ }^{11}$ illustrated by the dark gray lines pointed downward. There are also scrap recovery losses, which have been taken into account to yield the $290 \mathrm{Mt}$ of end-of-life scrap entering the system.

In the flow of steel to final products, a range of literature sources were used to estimate the copper tolerance range of each intermediate product stream. These tolerances quantify 


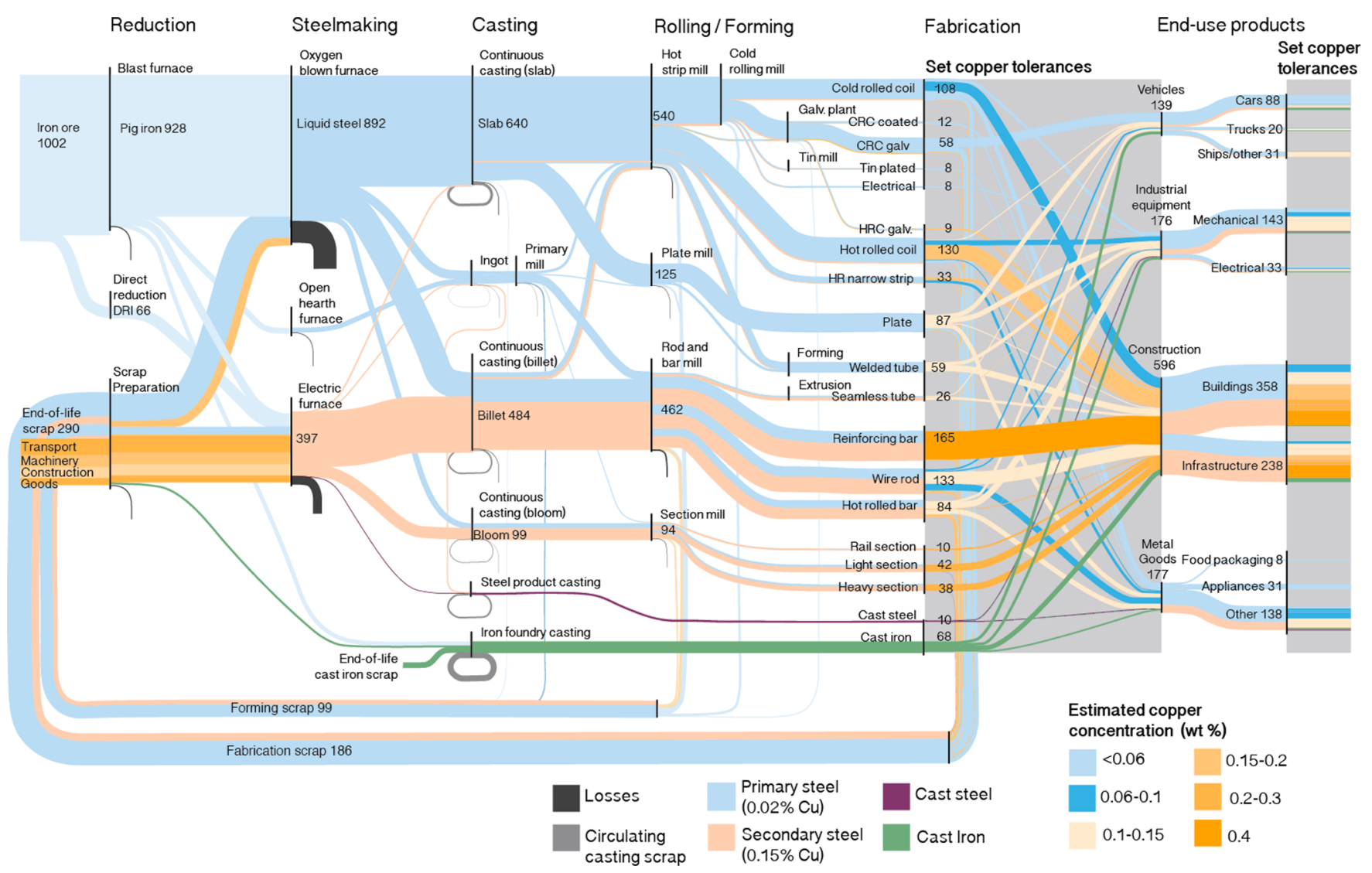

Figure 1. 2008 global steel flows (in Mt) with estimated copper concentrations of steel flows. The width of the flows corresponds to the mass processed per year. The gray boxes contain copper tolerance limits of intermediate and end-use products to compare copper in the system versus maximum tolerable. Section 2.1 of the SI provides the compilation of the various data sources that were reconciled to estimate the copper concentration of steel flows.

the capacity of the system to contain copper and serve as an indication of the likelihood of each product stream to contain copper-contaminated, end-of-life scrap.

2.2. The Future Global Steel System. Estimates for future global steel demand by sector are taken from Pauliuk et al., ${ }^{6}$ who applied a dynamic model to 10 world regions under the assumption that all regions will build their stocks of steel goods following the pattern of developed countries whose stocks have now largely saturated. Pauliuk et al. ${ }^{6}$ 's sensitivity analysis showed that calculated quantities can vary around $\pm 30 \%$ depending on input parameters, but overall trends in the growth in final steel demand and scrap supply proved to be robust. In this analysis a range of final steel demand quantities are therefore considered. Total final steel demand is varied $\pm 30 \%$, applied across all sectors. To show the effect of the sector's proportions, the construction sector's demand is increased $30 \%$, while the other sectors decrease by $30 \%$, and vice versa. Each sector's requirements by product type were estimated using the ratios determined by Cullen et al. ${ }^{11}$ The products (with castings excluded) were then categorized by quality (copper concentration allowable as determined in 2.1) and shape (flats and plates, tubes, shapes, and bars). The total amount of copper tolerated by the system was predicted from the mass requirement and copper tolerances of all products. The copper tolerance curve with best estimates is plotted, as well as a worst case with low tolerances applied across all products, and a best case calculated with high tolerance values.

Forecasts of end-of-life steel inputs to future recycling were taken from Pauliuk et al.'s ${ }^{6}$ predictions by end-use category, also determined using the stock-driven dynamic model with average product lifetimes and recovery rates. A similar sensitivity analysis was performed with these quantities, varying the total scrap supply quantity $\pm 30 \%$ and adjusting the proportion of the construction sector. For the influx of copper in a given year, the mass of end-of-life scrap supply by end-use category was multiplied by the expected concentrations in Table S21. The "estimated" curve shows when expected copper concentrations from current scrap handling practice can no longer be tolerated: the average concentration of scrap categories stays constant to 2100 , with a correction for when products with higher bulk copper concentrations eventually return for recycling (as reflected in Table S48). 80\% (average end-of-life recovery rate $)^{28}$ of the copper influx from 75 years ago (average product lifetime considering most EAF steels are used in construction $)^{29}$ was added to incoming construction scrap. Curves for high and low copper concentrations applied across all scrap categories are also plotted. From 1950 to 2100 the estimated copper in the supply and copper tolerated by demanded products can be compared. When two curves cross, a fraction of scrap is precluded from use, even allowing for perfect global distribution to tolerant applications and dilution. Forming and fabrication scrap is internal, not affecting the copper entering or leaving the system, and thus does not enter into these calculations.

A version of material pinch analysis is presented per annum by the decades to 2050 to show how categories of scrap and end-products could match, and the dilution that would be required for the best estimated case (using quantities presented 
by Pauliuk et al. ${ }^{6}$ and the concentrations for the scrap categories and product tolerances that were determined to be most likely). The mass of primary steel required each year is calculated as the difference between demand and the supply of end-of-life scrap. Demand is calculated as the final steel in finished products plus losses in refining and processing: an overall average of $12 \%^{11}$ was added to each product category to cover these losses.

2.3. End-of-Life Vehicles in the Global Steel System. The mass of ELVs (in Mt) entering the system in 2008 was estimated from the global scrap breakdown by Hatayama et al. $^{26}$ Although ELVs are prepared for recycling in a variety of ways and are often combined with other scrap sources, they are examined independently here, following the approach of the previous analysis. ${ }^{11}$ Upon reviewing vehicle scrap preparation practice and literature values, the global average copper concentration of ELVs was estimated and the flow of ELVs to end-use was determined by the copper tolerance of intermediate products. The steel required to make new cars in 2008 is traced, and the copper tolerances for new automotive steel production determined in section 2.1 was used to calculate the limits to ELV steel use.

\section{RESULTS}

The results are presented in the same sequence as the methodology development above.

3.1. Copper in the Global Steel System in 2008. Figure 1 shows global copper contamination, superimposed on Cullen et al.'s Sankey diagram of the global steel system in 2008. The gray box under "fabrication" shows the maximum copper tolerance of intermediate product streams. The gray box in the far right-hand side groups the tolerances of those streams by end-use products. The figure can then compare the likely flow of copper in the system with tolerance limits. For example, it can be seen that buildings are likely made from $40 \%$ secondary steel, at an average of 0.15 wt \% copper while the box to the right shows the intermediate products making up buildings could (in 2008) tolerate a higher proportion of secondary steel at a higher copper concentration. All contaminated scrap can be distributed to demanded products, with the scope for absorbing more copper residing mostly in buildings and infrastructure. The total quantity of copper in the system is about $0.7 \mathrm{Mt}$, while $1.8 \mathrm{Mt}$ could be tolerated. Figure 1 also shows that endof-life vehicles are the most potent contaminating source to the steel system, while new cars are the main end-use behind the demand for the highest quality steels, originating almost exclusively from the primary route.

3.2. Copper in the Future Global Steel System. Figure 2 shows the estimated mass of copper in the scrap supply and copper that can be tolerated by end-use products, as well as curves varying from this estimated case, from 1950 to 2100 .

There is a substantial range exhibited by the curves such that when steel recycling will be globally constrained by copper concentration cannot be defined, but best estimates indicate 2050. Applying low concentrations across scrap categories could effectively delay constraints to 2100, while assuming higher values could advance the crossover to before 2030 . There are combinations of curves that do not cross, for example if the scrap supply is reduced by $30 \%$ and final steel demand is increased by $30 \%$. The curves plotted represent extreme cases. Figures S10 and S11 show the significantly smaller range of uncertainty when the distribution of concentrations is applied individually to scrap categories and end-products. Even

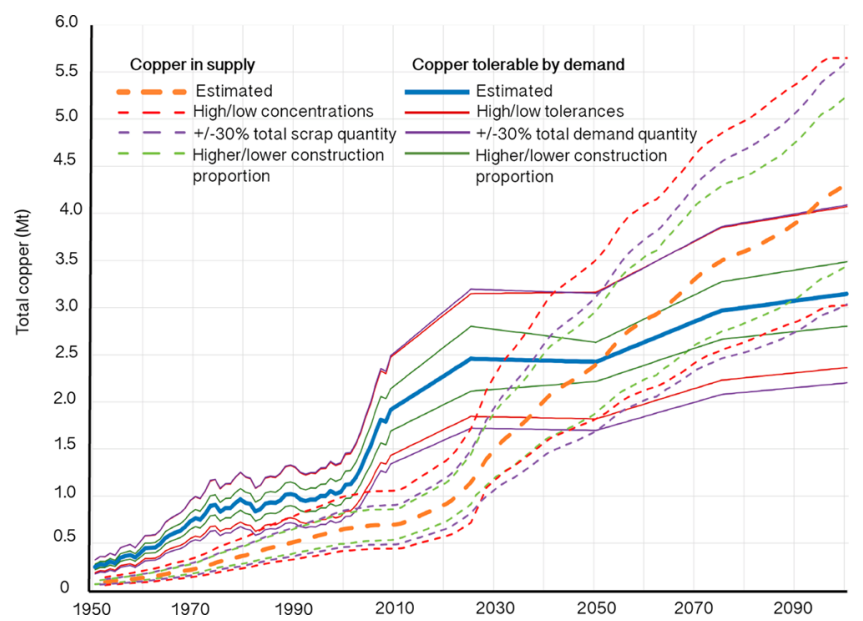

Figure 2. Mass of copper in the end-of-life scrap supply and copper tolerable by demanded products from 1950 to 2100 . The estimated case uses sectoral final steel demand and scrap supply quantities as determined by Pauliuk et al.'s ${ }^{6}$ global stock-saturation model, Cullen et al.'s ${ }^{11}$ product to sector mapping, and expected values of copper concentration for scrap categories and product tolerances as determined through a literature survey. Sensitivity curves apply high and low values for copper concentration across all categories, vary the total quantities of end-use steel demand and scrap supply across all sectors $\pm 30 \%$, and vary the proportion of the construction sector by $\pm 30 \%$ (while other sectors decrease/increase by $30 \%$, respectively).

allowing these large uncertainty ranges, the trend is clear: there is a large difference between copper in the supply and copper tolerated by end-products today due to the substantial increase in primary production since the early 2000s. The amount of copper tolerated by end-use products begins to plateau in 2025, while copper in the scrap supply invariably increases. The greater number of research projects to address copper contamination in the past can also be explained: the difference between the curves was smaller before 2000 .

Figure 3 provides snapshots of projected masses of iron sources (inputs into the steel system, left-hand side of the Sankey diagram) and end products (outputs of the steel system, right-hand of the Sankey diagram plus losses) per annum for the next few decades calculated from the best estimates scenario. The masses of steel in each category are plotted by copper concentration to visualize the possible destiny of scrap sources to meet demand. In 2008 and 2020, it can be seen that all end-of-life scrap can be used in products with tolerances greater than 0.15 wt \% copper. By shape, all end-of-life scrap can be used for bars. By 2030 end-of-life scrap must be used for 0.1-0.15 wt \% copper-tolerant products, and incoming construction scrap will have a higher concentration of copper due to past accumulation. In balancing copper in the sources over products, there exists capacity for accepting more copper in the 0.4 wt \% category, which would mean further concentrating copper-containing sources, while the excess purity from pig iron would be utilized through dilution. 2030 marks the beginning of when dilution and distribution of scrap to the various product categories will be necessary on a global scale. By 2050 the total copper in the supply is forecast to be about the same as the maximum that can be tolerated across all products and to match supply with demand, scrap will have to be cast and rolled into flat and plate products.

Figure 4 plots the masses of several of the categories from Figure 3 to compare the relative growth rates. As the scrap 


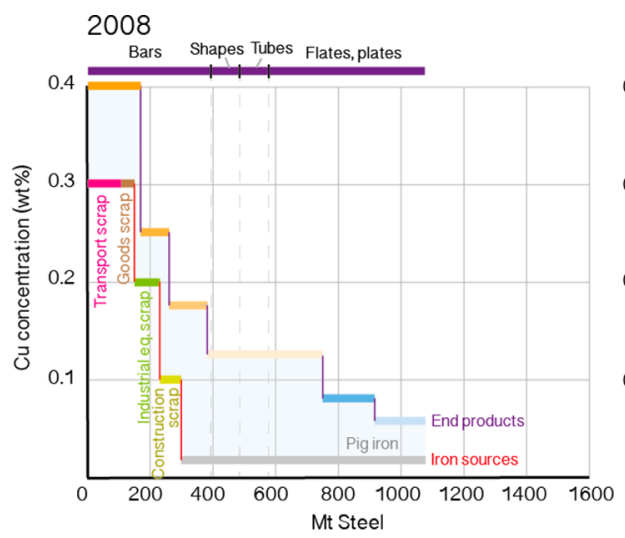

2020
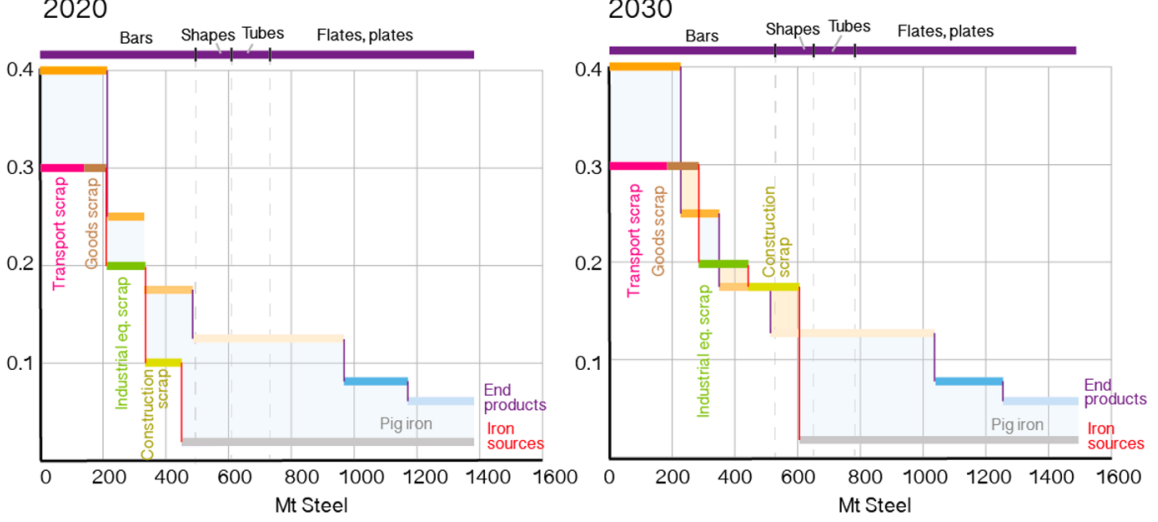
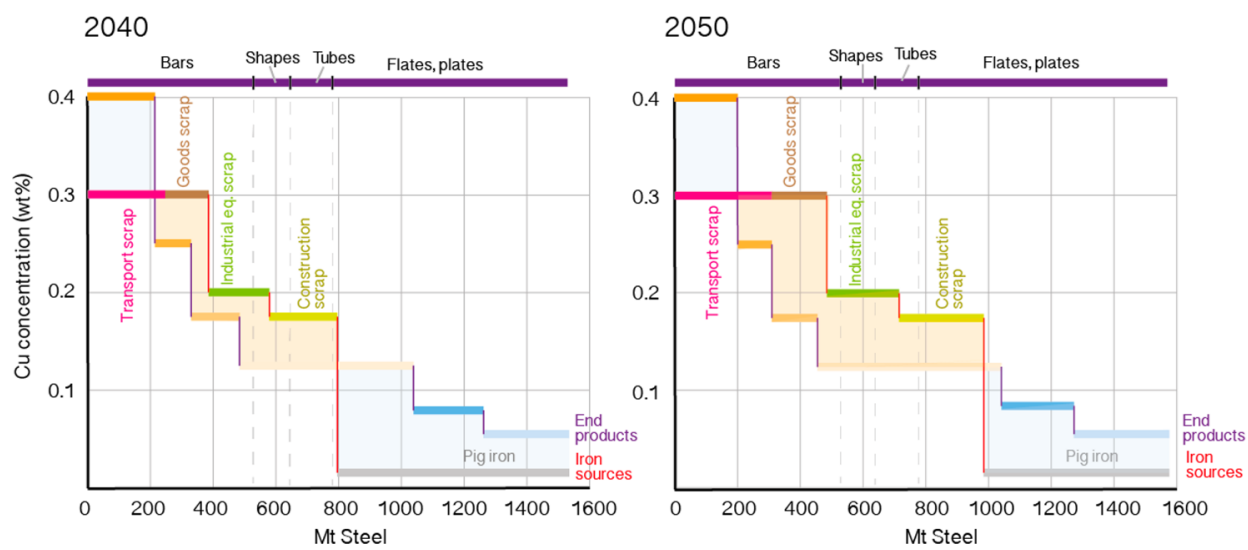

Excess copper (requires dilution)

Excess purity (capacity to absorb more copper)

Figure 3. Projected masses of iron sources (end-of-life scrap and pig iron) and finished steel products in end-use, as determined through Pauliuk et al.'s ${ }^{6}$ global stock-saturation estimates and Cullen et al.'s ${ }^{11}$ product to sector matrix, plotted by expected copper concentration for 2008, 2020, 2030, 2040, and 2050. For end-products, the copper concentration is the expected tolerance. Gaps between the source and end product curves indicate either where dilution is required (orange), or where more copper could be tolerated by the end-use (blue). Masses of end products by shape are plotted above. An additional mass of $12 \%$ was added to each end product category to account for iron sources that would be lost (and not recovered in circulation scrap) in refining and processing.

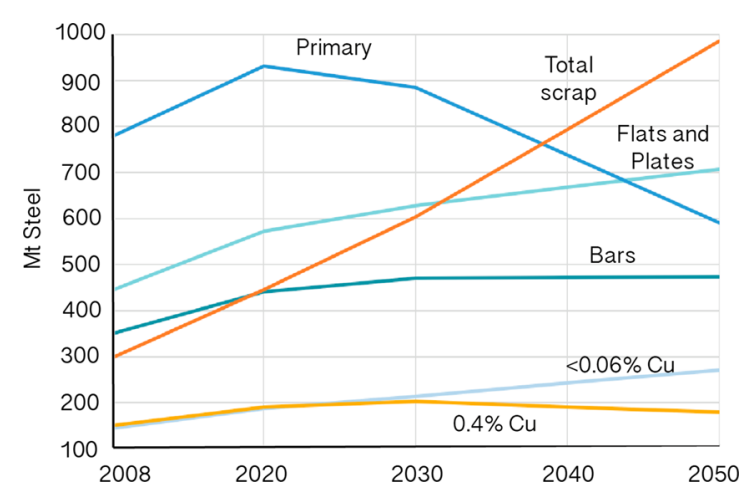

Figure 4. Trends in projected masses $(\mathrm{Mt})$ of steel categories (required primary, total scrap, products requiring $<0.06 \%$ copper and $>0.4 \%$ copper) from 2008 to 2050 , as determined through Pauliuk et al. ${ }^{6}$ 's global stock-saturation estimates and Cullen et al.'s ${ }^{11}$ product to sector matrix.

volume grows the amount of primary material required to make up the difference between the scrap supply and demanded end products decreases. Concurrently, demand for the product categories best able to absorb copper (tolerances $>0.4 \% \mathrm{Cu}$ and bars) plateau or decrease slightly in mass, while categories least tolerant (tolerances $<0.06 \% \mathrm{Cu}$ and flats/plates) continue to expand to 2050 .

3.3. End-of-Life Vehicles in the Global Steel System. Figure 5 shows steel flows involved in producing new cars and recycling end-of-life vehicles in 2008, layered with a theoretical closed-loop. In current practice, with an estimated copper concentration of $0.4 \%$, reinforcing bars are the only viable use of ELVs without dilution. ELVs could be used to produce up to $48 \mathrm{Mt}$ of the $165 \mathrm{Mt}$ of reinforcing bar demanded globally in 2008. Galvanized cold rolled coil requiring less than $0.06 \%$ copper, and bars, tubes and wire rods allowing up to $0.1 \%$ copper are the main intermediate products in cars. Therefore, to achieve a closed loop the material salvaged from ELVs should have a copper concentration of less than $0.08 \%$, requiring removal of $0.19 \mathrm{Mt}$ of copper. Using ELV scrap for the production of new vehicles would reduce the amount of iron ore required from 136 to $78 \mathrm{Mt}$, accounting for $32 \mathrm{Mt}$ of fabrication scrap generated in car manufacturing.

\section{DISCUSSION}

Copper contamination constrains recycled steel to serve a segregated market, as illustrated in Figure 1, but demand for steel products with high copper tolerance easily accommodates contaminated scrap. However, using future projections assuming global stock saturation, there is a clear trend toward increased difficulties and inefficiencies caused by copper. Within this global context, strategically trading scrap to applications with sufficient demand has a limit. Best estimates show copper contamination could theoretically be managed until 2050, assuming perfect distribution of copper in the global steel system. However, in this case extensive dilution and 


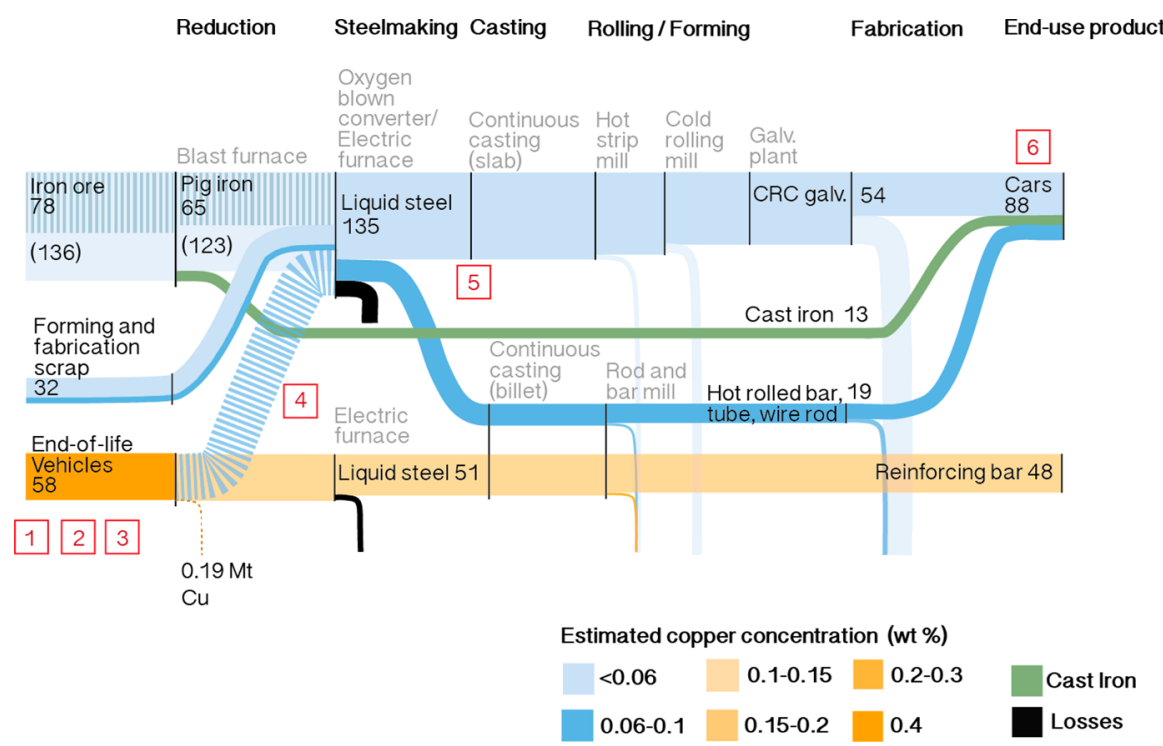

Figure 5. Steel mass flows (in Mt) corresponding to the production of cars and the recycling of end-of-life vehicles traced through the 2008 global steel system, both current practice and a theoretical closed-loop. In the closed-loop, indicated by dashed flows, ELVs are not used for reinforcing bar production. The red numbers represent technical interventions along the supply chain to achieve a closed-loop: (1) more disassembly, (2) better shredding, (3) better sorting, (4) chemical extraction, (5) increase tolerance, and (6) reduce copper content.

careful allocation of scrap at a global scale would be required by 2030, as shown in Figure 3.

As the demand for copper-tolerant products (such as reinforcing bars) is likely to grow at a slower rate than demand for higher quality steels (such as those used in the production of cars) interventions will eventually be necessary to avoid accumulating stocks of unusable steel scrap. As shown in Figure 3 , the $0.4 \% \mathrm{Cu}$ category (reinforcing bar) cannot contain all transport scrap after 2040. The analysis of this paper has given detail about product categories but is not spatially explicit. Generally, high volumes of mechanically processed, end-of-life scrap are available in developed countries, but here demand for high quality, flat steel products is greater so this demand cannot be met by recycling local scrap. Developing countries that require more long, construction-grade products do not generate as much end-of-life scrap that could supply this production, and scrap with higher copper concentrations could be tolerated. These imbalances are evidenced in composition measurements of EAF steel bars from China and Japan. Daigo and Goto ${ }^{30}$ show significantly higher concentrations of tramp elements in Japan than China. Future analysis could explore regional variations within the context of global trading, as demonstrated by Pauliuk et al., ${ }^{16}$ to understand the trading and asset needs of countries at different stages of their development cycles.

The secondary result of the paper is that closed-loop recycling of automotive steel is currently unlikely, and this provides motivation to address current practice before the global constraining point is met. A range of technical and policy interventions if implemented now could create the basis for a more effective global steel recycling strategy over the next two decades. These opportunities for intervention are reviewed in detail in the SI and summarized here. Commonly practiced hammer shredding pounds copper wiring onto steel, such that subsequent magnetic separation is only $80 \%$ effective. However, further disassembly could remove copper-containing parts prior to shredding. ${ }^{34}$ Alternative shredding processes exist, and technologies such as laser-induced breakdown spectroscopy, ${ }^{35}$ $\mathrm{X}$-ray fluorescence, neutron activation analysis, ${ }^{36}$ or image processing of a conveyor belt of scrap can be applied to help sort copper-rich pieces, or more precisely determine the composition of a batch to allow for strategic upgrading and batching before melting. In current EAF steelmaking and refining copper remains in the melt, but it is not fundamentally irremovable, as mechanisms beyond oxidation (such as vaporization, ${ }^{37}$ or forming a copper sulfide ${ }^{38}$ or chloride ${ }^{39}$ ) could be employed. The copper tolerance of products could be increased by manipulating processing (i.e., shorter oxidation times and surface quenching) and composition (adding nickel or silicon and avoiding tin) to overcome hot shortness. ${ }^{9}$ This has been the approach of Nucor, the largest steel recycling company in the United States, who have been able to penetrate the automotive steel market with EAF steel. Lastly, vehicle design changes could reduce the need for downstream interventions. Copper usage in cars has been increasing, with electric and hybrid vehicles containing twice the copper content of an average vehicle. ${ }^{40}$ Designs exist for weight-saving aluminum wire harnesses, ${ }^{41}$ as well as for the wiring wrapping around the vehicle to be detachable with one mechanical motion. ${ }^{42}$ Trade-offs of technologies for improved copper removal are summarized in Figure 6.

As these interventions are more costly than current practice, policy should be considered to incentivize their adoption. Quality measures are not explicit in regulations. The European Union End-of-Life Vehicle Directive ${ }^{43}$ set targets for 2015 onward that $95 \%$ of ELV material by mass must go for recovery, reuse and recycling. Mass-based policies are counterproductive for impurity and alloying element control. A policy that focuses on the most environmentally impactful parts of a vehicle and monitors for quality and dilution losses should be developed. For example, a recent Japanese law on the recycling of small waste electronic equipment that measures the recovery of specific scarce metals. ${ }^{15}$ The EU ELV Directive has mandated the removal of fluids prior to shredding and has measurably improved the control of hazardous substances, ${ }^{44}$ so this regulation could also be extended to contaminating metals. 


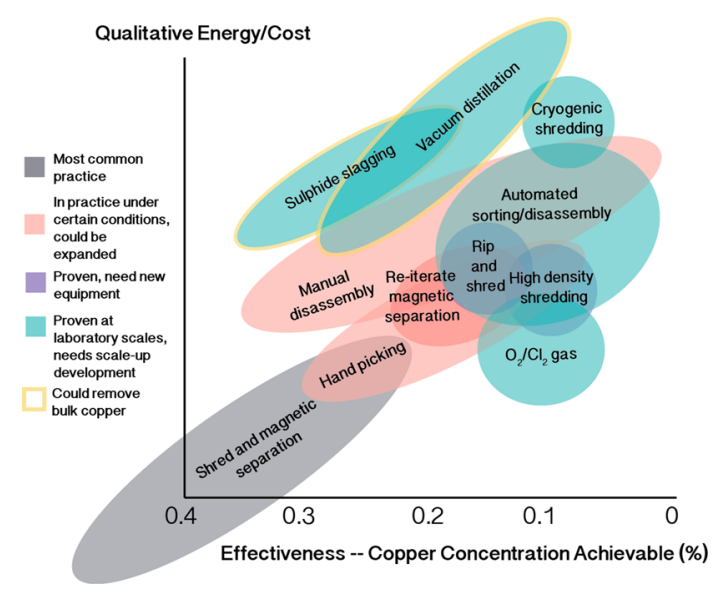

Figure 6. Comparison by copper concentration achievable and estimated relative energy and cost of the discussed copper separation interventions. Reasoning behind the placement of each technology is provided in Table S50.

Quality-based pricing of scrap could ensure the advantage steelmakers gain from clean scrap is shared with the scrap processor. Though steelmakers and suppliers establish relationships to ensure respective needs are met, the classification system they operate within could be improved. There are nominal limits for the concentration of tramp elements, but actual concentrations deviate. For example, “\#2 heavy melting steel" is classified identically whether it has $0.2 \% \mathrm{Cu}$ or $0.4 \%$ $\mathrm{Cu}^{45}$ There are technological limitations in measuring of the concentration of tramp elements in solid scrap in real time, but this could be an area for future development. Furthermore, improved control of ELV scrap would allow for retention of high embodied-energy ${ }^{31}$ and economically and geopolitically important $^{32}$ alloying elements specific to automotive applications, which are dissipated when cars are recycled to structural steels. $^{33}$

It cannot be determined with certainty when copper contamination will prevent the utilization of end-of-life scrap, as assumptions must be made about future quantities of steel and their compositions. These sources of uncertainty are identified and discussed in Section S4.2 of the SI. However, work characterizing current and future steel flows from a physical basis can provide a sound premise for qualitatively understanding what is most likely to happen in the future. Results must be interpreted at an aggregated, high level, but reveal important long-term trends. As long as copper remains in the steel melt during refining, it will remain in the cycle once embedded in products, and many steel products have long lifetimes-thus current actions will have long-term consequences. Contextualizing the problem shows that the steel industry has been in a state of relative ease in tolerating copper contamination, but copper will cause increasingly greater inefficiencies, with a global effort in diluting and carefully distributing scrap sources most likely required by 2030 . Forward-thinking and careful investment in the development and deployment of processes and policies to manage copper in the steel system will be necessary to avoid an accumulation of unusable scrap.

The constraining point for copper contamination depends on the balance of production between blast furnace and EAF routes. The analysis of this paper has assumed that all recovered scrap will be recycled, with blast furnace production supplying all other requirements, and that demand grows according to current stock saturation patterns. However, if concern about climate change leads to real action on limiting emissions and this is applied across sectors, then blast furnace production must be reduced. With a model of global mass flow and process emissions intensities, Milford et $\mathrm{al}^{4}{ }^{4}$ concluded that currently legislated emissions abatement targets could only be achieved by an aggressive reduction in primary steel production to about $300 \mathrm{Mt} /$ year by 2050 . This is around half the anticipated figure in the demand forecast used in this paper and if implemented would greatly increase the urgency for action on copper contamination.

\section{ASSOCIATED CONTENT}

\section{S Supporting Information}

The Supporting Information is available free of charge on the ACS Publications website at DOI: 10.1021/acs.est.7b00997.

A full literature review, survey and application of data sources, additional results, and error analysis as well as a detailed review of interventions (PDF)

\section{AUTHOR INFORMATION}

\section{Corresponding Author}

*E-mail: jma42@cam.ac.uk (J.A.).

ORCID

Julian M. Allwood: 0000-0003-0931-3831

Notes

The authors declare no competing financial interest.

\section{ACKNOWLEDGMENTS}

K.D. is funded by a Cambridge Trust scholarship. A.S. and J.A. are funded by EPSRC, grant reference EP/N02351X/1.

\section{REFERENCES}

(1) Graedel, T. E. UNEP Recycling rates of metals-A Status Report, a Report of the Working Group on the Global Metal Flows to the International Resource PanelUnited Nations Environment Programme, 2011.

(2) Yellishetty, M.; Mudd, G. M.; Ranjith, P. G.; Tharumarajah, A. Environmental life-cycle comparisons of steel production and recycling: Sustainability issues, problems and prospects. Environ. Sci. Policy 2011, 14 (6), 650-663.

(3) Allwood, J. M.; Cullen, J. M.; Milford, R. L. Options for achieving a $50 \%$ cut in industrial carbon emissions by 2050 . Environ. Sci. Technol. 2010, 44 (6), 1888-1894.

(4) Milford, R. L.; Pauliuk, S.; Allwood, J. M.; Müller, D. B. The roles of energy and material efficiency in meeting steel industry $\mathrm{CO} 2$ targets. Environ. Sci. Technol. 2013, 47 (7), 3455-3462.

(5) Oda, J.; Akimoto, K.; Tomoda, T. Long-term global availability of steel scrap. Resources, Conservation and Recycling 2013, 81, 81-91.

(6) Pauliuk, S.; Milford, R. L.; Müller, D. B.; Allwood, J. M. The steel scrap age. Environ. Sci. Technol. 2013, 47 (7), 3448-3454.

(7) Allwood, J. The future of steel: time to wake up. Materials World 2016, 24 (1), 44-47.

(8) Nakajima, K.; Takeda, O.; Miki, T.; Matsubae, K.; Nagasaka, T. Thermodynamic analysis for the controllability of elements in the recycling process of metals. Environ. Sci. Technol. 2011, 45, 49294936.

(9) Rod, O.; Becker, C.; Nylén, M. Opportunities and dangers of using residual elements in steels: a literature survey. Jernknotoret Report 88042 2006, 1-59.

(10) Savov, L.; Volkova, E.; Janke, D. Copper and tin in steel scrap recycling. Materials Geoenvironment 2003, 50 (3), 627-640. 
(11) Cullen, J. M.; Allwood, J. M.; Bambach, M. D. Mapping the global flow of steel: from steelmaking to end-use goods. Environ. Sci. Technol. 2012, 46 (24), 13048-55.

(12) Björkman, B.; Samuelsson, C. Recycling of Steel. In Handbook of Recycling; Worrell, E., Reuter, M., Eds.; Elsevier: Oxford, UK, 2013; pp $65-83$.

(13) Schrade, C.; Huellen, M.; Wilhelm, U.; Zulhan, Z. EAF-Based Flat-Steel Production Applying Secondary Metallurgical Processes. Linz/Austria October Secondary Steelmaking Session. 2006, Paper No. 7.1.103 (10), 445-45110.1051/metal:2006167.

(14) Katayama, H.; Sano, N.; Sasabe, M.; Matsuoka, S. Research Activities on Residual Element Removal Japan Iron and Steel-Today, Yesterday, and Tomorrow. (Stockholm 11-14 June) Conference Proceedings. 1997, 1, 15-26.

(15) Nakamura, S.; Kondo, Y.; Matsubae, K.; Nakajima, K.; Tasaki, T.; Nagasaka, T. Quality- and dilution losses in the recycling of ferrous materials from end-of-life passenger cars: Input-output analysis under explicit consideration of scrap quality. Environ. Sci. Technol. 2012, 46 (17), 9266-9273.

(16) Pauliuk, S.; Kondo, Y.; Nakamura, S.; Nakajima, K. Regional distribution and losses of end-of-life steel throughout multiple product life cycles-Insights from the global multiregional MaTrace model. Resources, Conservation and Recycling 2017, 116, 84-93.

(17) Noro, K.; Takeuchi, M.; Mizukami, Y. Effects of $\mathrm{Cu}$ and Other Tramp Elements on Steel Properties. Necessity of Scrap Reclamation Technologies and Present Conditions of Technical Development. ISIJ Int. 1997, 37 (3), 198-206.

(18) Kakudate, K.; Adachi, Y.; Suzuki, T. A macro model for usage and recycling pattern of steel in Japan using the population balance model. Sci. Technol. Adv. Mater. 2000, 1 (2), 105-116.

(19) Pauliuk, S.; Wang, T.; Müller, D. B. Moving toward the circular economy: The role of stocks in the Chinese steel cycle. Environ. Sci. Technol. 2012, 46 (1), 148-154.

(20) Matsubae, K.; Nakajima, K.; Nakamura, S.; Nagasaka, T. Impact of the Recovery of Secondary Ferrous Materials from Alternative ELV Treatment Methods on CO2 Emission: A Waste Input Output Analysis. ISIJ Int. 2011, 51 (1), 151-157.

(21) Igarashi, Y.; Daigo, I.; Matsuno, Y.; Adachi, Y. Estimation of the change in quality of domestic steel production affected by steel scrap exports. ISIJ Int. 2007, 47 (5), 753-757.

(22) Söderholm, P.; Ejdemo, T. Steel scrap markets in Europe and the USA. Minerals \& Energy-Raw Materials Report 2008, 23 (2), 5773.

(23) Ekvall, T.; Fråne, A.; Hallgren, F.; Holmgren, K. Material pinch analysis: a pilot study on global steel flows. Metall. Res. Technol. 2014, 111 (6), 359-367.

(24) Nakamura, S.; Kondo, Y.; Kagawa, S.; Matsubae, K.; Nakajima, K.; Nagasaka, T. MaTrace: Tracing the fate of materials over time and across products in open-loop recycling. Environ. Sci. Technol. 2014, 48 (13), 7207-7214.

(25) Schmidt, M. The Sankey diagram in energy and material flow management, part II: methodology and current applications. J. Ind. Ecol. 2008, 12 (2), 173-185.

(26) Hatayama, H.; Daigo, I.; Matsuno, Y.; Adachi, Y. Outlook of the world steel cycle based on the stock and flow dynamics. Environ. Sci. Technol. 2010, 44 (16), 6457-6463.

(27) USGS, Iron and Steel Statistics and Information 2010. United States Geological Survey Annual Publications; http://minerals.usgs. gov/minerals/pubs/commodity/iron_\&_steel/.

(28) WSA, Steel and Raw Materials Fact Sheet; worldsteel Association, 2010; https://www.worldsteel.org/publications/fact-sheets.html.

(29) Pauliuk, S.; Wang, T.; Müller, D. B. Steel all over the world: Estimating in-use stocks of iron for 200 countries. Resources, Conservation and Recycling 2013, 71, 22-30.

(30) Daigo, I.; Goto, Y. Comparison of Tramp Element Contents of Steel Bars from Japan and China. ISIJ Int. 2015, 55 (9), 2027-2032.

(31) Holappa, L. Towards sustainability in ferroalloy production. Journal of the Southern African Institute of Mining and Metallurgy 2010, $110,6-9$.
(32) Critical raw materials for the EU - Annex $V$ to the Report of the Adhoc Working Group on defining critical raw materials; European Commission, 2012; https://ec.europa.eu/growth/tools-databases/eipraw-materials/en/community/document/annex-v-report-ad-hocworking-group-defining-critical-raw-materials.

(33) Ohno, H.; Matsubae, K.; Nakajima, K.; Nakamura, S.; Nagasaka, $\mathrm{T}$. Unintentional flow of alloying elements in steel during recycling of end-of-life vehicles. J. Ind. Ecol. 2014, 18 (2), 242-253.

(34) Coates, G.; Rahimifard, S. Assessing the economics of prefragmentation material recovery within the UK. Resources, Conservation and Recycling 2007, 52 (2), 286-302.

(35) Gurell, J.; Bengtson, A.; Falkenström, M.; Hansson, B. Laser induced breakdown spectroscopy for fast elemental analysis and sorting of metallic scrap pieces using certified reference materials. Spectrochim. Acta, Part B 2012, 74-75 (0), 46-50.

(36) Gamma-Tech Website; http://www.gammatech.us/Analyzer. aspx.

(37) Savov, L.; Janke, D. Evaporation of $\mathrm{Cu}$ and $\mathrm{Sn}$ from Inductionstirred Iron-based Melts Treated at Reduced Pressure. ISIJ Int. 2000, 40 (2), 95-104.

(38) Wang, C.; Nagasaka, T.; Hino, M.; Ban-Ya, S. Copper Distribution between Molten FeS-NaS0.5 Flux and Carbon Saturated Iron Melt. ISIJ Int. 1991, 31 (1), 1300-1308.

(39) Hu, X.; Yan, Z.; Jiang, P.; Zhu, L.; Chou, K.; Matsuura, H.; Tsukihashi, F. Removal of Copper from Molten Steel using FeO-SiO2$\mathrm{CaCl} 2$ Flux. ISIJ Int. 2013, 53 (5), 920-922.

(40) Copper Facts, Copper Development Association; https://www. copper.org/education/c-facts/facts-print.html.

(41) Oba, K. Wiring Harnesses for Next Generation Automobiles. Fujikura Tech Rev. 2013, 42, 77-80.

(42) Toyota. Toyota's Environmental Initiatives: Contribution to a Recycling-Based Society, 2015; pg. 32; http://www.toyota-global. com/sustainability/report/er/pdf/er15_04_en.pdf.

(43) 2000/53/EC of the European Parliament and the council of 18 September 2000 on end of life vehicles; Official Journal of the European Communities; 21-10-2000; European Commission, 2000.

(44) Gerrard, J.; Kandlikar, M. Is European end-of-life vehicle legislation living up to expectations? Assessing the impact of the ELV Directive on "green" innovation and vehicle recovery. J. Cleaner Prod. 2007, 15 (1), 17-27.

(45) Institute of Scrap Recycling Industries (ISRI); Scrap Specifications Circular, 2016; http://www.isri.org/docs/defaultsource/commodities/specsupdate.pdf.

(46) Gesing, A. Assuring the continued recycling of light metals in end-of-life vehicles: A global perspective. JOM 2004, 56, 18-27.

(47) Worldsteel Association. Future of ferrous scrap availability and demand. IOM3 Steel Strategy Seminar Series 2-4, London, 2016. 